\title{
PSYCHE.
}

\section{THE MOUTHPARTS OF THE NEMATOCEROUS DIPTERA, V.}

\author{
BY VERNON L. KELLOGG, STANFORD UNIVERSITY.
}

RESUME.

Having examined the mouth structure of representatives of all (except one) of the families of Nematocerous Diptera we are in position to state in general and inclusive terms the characters of the mouthparts of the Nematocera.

The mouthparts are composed of (retaining the nomenclature heretofore used) a labrum-epipharynx, a pair of mandibles, wanting in the males of all families, and wanting in both sexes of a few families, a pair of maxillae, in which never more than one terminal lobe is present, and this failing in a few instances, and a labium, whose palpi are totally lost, and whose terminal lobes show a considerable range in degree of coalescence. The condition of the various parts may be described in more detail as follows:

The labrum-epipharynx is always present and always free; it is longer than broad, pointed though not always sharply, and, as seen from above, wellchitinized. It is composed of two lamellae (often separable by dissection, or by treatment with potassium or sodium hydrate) of which the upper or dorsal one is a well chitinized sclerite and is the labrum s. str. The lower or ventral one is a thin membranous structure, often projecting slightly beyond the labrum and in almost all cases bearing few or numerous taste pits (?) and papillar sense (?) hairs.

The mandibles are, when present, possessed only by the females; they are wanting in both sexes in six of the eleven families studied. The mandibles in the five families possessing them are always free and distinct but show very obviously their tendency toward reduction and disappearance. In their best developed and certainly effectively functional condition, they are long, slender, well-chitinized and armed with a fine but conspicuous dentation along their inner margin. From this condition they descend by quick steps to the condition of small thin weakly-chitinized delicate plates, practically functionless. 
The maxillae are always free except at their very base: they possess a basal sclerite, never separable into cardo and stipes, a palpus always welldeveloped and 4 or 5 -segmented, and a single maxillar lobe, which is wanting in a few cases. When present, this lobe is a slender, elongate, weaklychitinized, thin, flat, process, with pointed and "fringed" apex. It shows gradual degrees of reduction to total disappearance.

The labium is a free, short (but little longer than broad) under lip, with basal sclerite only rarely showing indications of its composition of two parts (sub-mentum and mentum) and with terminal lobes showing various degrees of coalescence with each other. The base of the labium is in some instances united by membranes with the bases of the maxillae. Palpi are always wanting; no unmistakable indications of them are to be found, although in two forms examined, what may be palpar rudiments are present. The terminal lobes in freest condition consist of the two free paraglossae sometimes apparently 2 -segmented, and a median, always delicate, membranous lobe representing the fused glossae. The paraglossae when free, as is the condition in almost all the Nematocera, show no indications of pseudo-tracheae and are rather thick, concave on their inner faces, and more or less thickly beset with hairs of varying size and strength. In one family the paraglossae tend to coalesce, and within the limits of this one family (the Tipulidae) the paraglossae may be found free, partly coalesced and coalesced almost completely. With the beginning of coalescence, appears the first indications of pseudo-tracheae, and in the nearly completely coalesced condition, the system of pseudo-tracheae is well developed.

The hypopharynx is probably always present (in one or two instances I have been unable to dissect it out satisfactorily on account of its minute size and delicacy). It is a delicate, membranous, elongate, pointed plate, in which the course and opening of the salivary duct can usually be seen. It is always free from its base, arising from the inner (upper) wall of the lahium to its tip.

\section{Homologies and Phylogeny.}

The homologies of the various mouthparts within the group Nematocera seem obvious and certain. The differences between the mouthparts of Blepharocera, Simulium, and Ceratopogon in which mandibles and a functional maxillar lobe are present, and the mouthparts of Bibio and Tipula in which there are no mandibles and no maxillar lobe is simply one of degree of specialization by reduction. Similarly the single, broad lobe with elaborate system of pseudo-tracheae which constitutes the labium of Tipula simply presents the extreme degree of coalescence (as reached among the Nematocera) of the outer terminal labial lobes, the para- 
glossae, which in Simulium, Rhyphus, Dixa, and even in Symplecta (a Tipulid) are free and distinct, and without sign of pseudo-tracheae. The gradual coalescence of paraglossae is seen plainly in Mycetophila and among the Tipulids, and the gradual appearance of the pseudo-tracheae can be readily traced in the Tipulid family. The general tendency of specialization of the mouthparts of the Nematocera is toward the reduction and loss of the mandibles and maxillae, and toward the special development of the labium to be a rasping, lapping organ, all-important in food taking. The physiological change in food habit from blood-taking or sap sucking, which demands piercing and elongate sucking parts, to the lapping of exposed liquids or the taking of solid food in small rasped-off particles mixed with a salivary or other secreted fluid, has been accompanied by the general structural change already indicated.

Now, is the highly specialized mouth of the Muscidae and other similar Brachycerous Diptera reducible to the $\mathrm{Ne}$ matocerous mouth? Can the parts of the mouth of Musca be homologized with the parts of the Nematocerous mouth? To display the evidence which the comparative anatomy of the mouthparts presents touching the point will require another paper. It is necessary to present the gradations between the most specialized of the Nematocerous mouths, say that of Tipula, and the mouth of Musca. I may only say here that to any one at all acquainted with the Dipterous mouthparts this will not be taken to be a very difficult matter.

Finally, can the Nematocerous mouth be reduced to the orthopterous, biting type of mouth? Are the so-called mandibles, maxillae and labium of Blepharocera or Ceratopogon homologous with the mandibles, maxillae and labium of a cockroach? Unfortunately there is no persistent racial genus of flies with orthopterous mouthparts, like Eriocephala among the Lepidoptera. The persistence of Eriocephala enables the development of the highly specialized mouth structure of the butterfly to be traced backward through the higher moths, through the Tineids, and finally through Eriocephala directly to the orthopterous type. Comparative anatomy can here unaided satisfactorily reveal the homologies.

But with the Diptera the most generalized mouth is far from the orthopterous type. And yet it seems not unreasonable, nor violently imaginative to see in the mouth of Blepharocera, the modified but still recognizable mandibulate mouth. However, a study of the development, the ontogeny of the mouthparts of some Nematocerous form is necessary to present the needed confirmation of this supposition, and this testimony of the ontogeny I hope to present in some future paper.

As said at the beginning of these notes, the scope of this paper is limited to the study of the comparative anatomy of the mouthparts of the Nematocerous Diptera. 

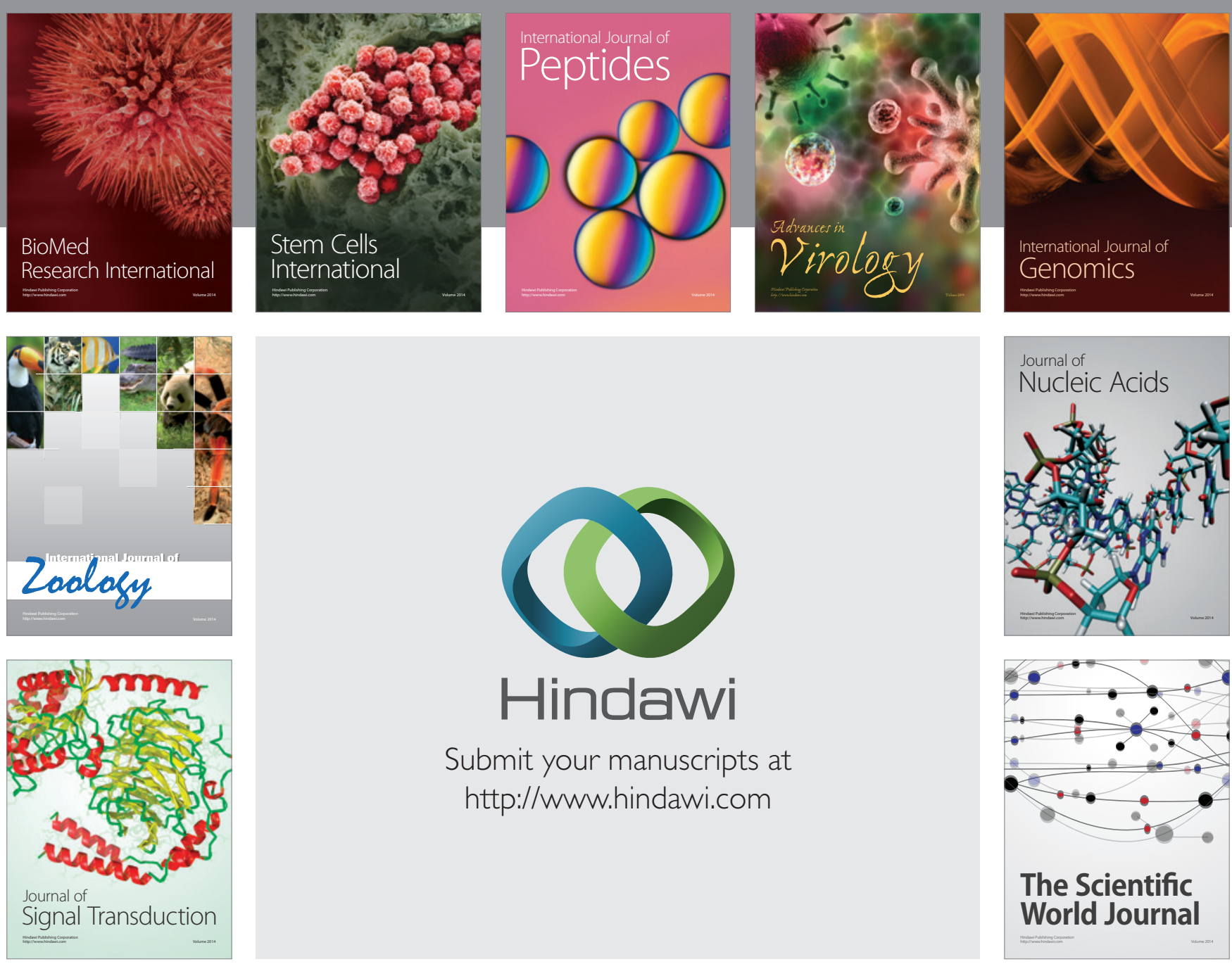

Submit your manuscripts at

http://www.hindawi.com
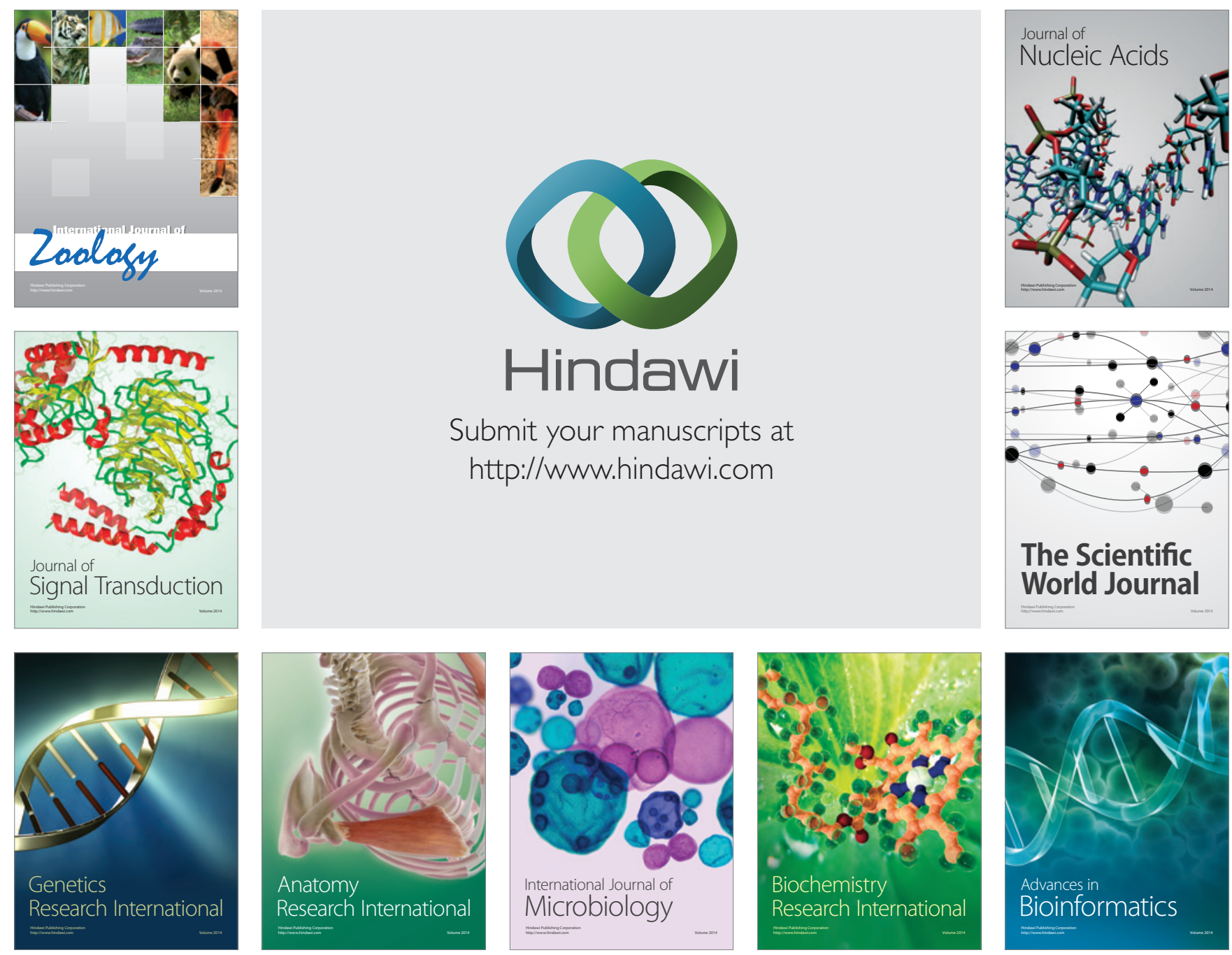

The Scientific World Journal
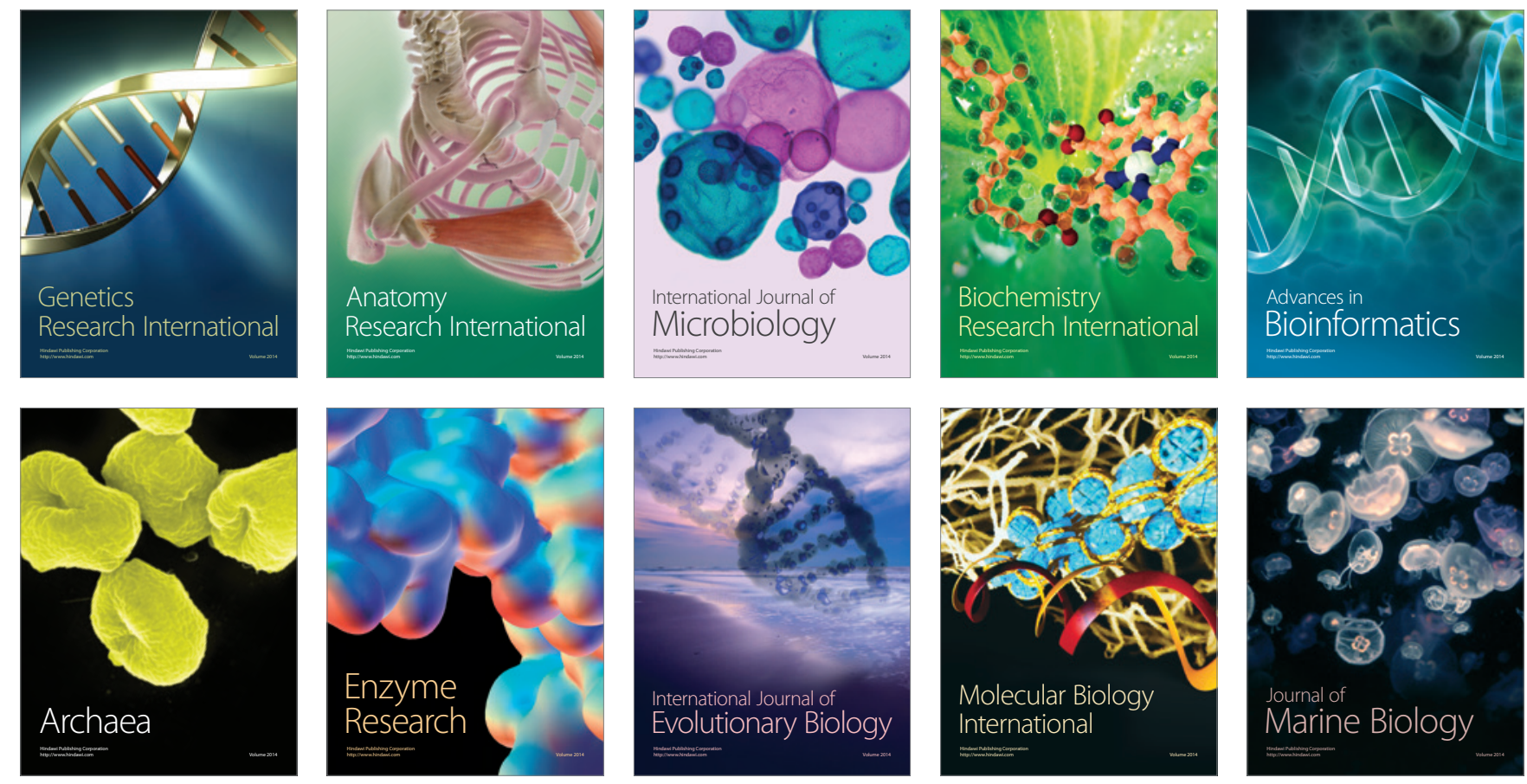